\title{
O papel da Tecnologia da Informação (TI) e a influência dos processos de aprendizado e de geração de conhecimento: um estudo de caso em uma empresa do setor elétrico brasileiro.
}

\author{
André Machado Dias Ferreira \\ Aluno do MBA em Gestão de Operações da Fundação Carlos Alberto Vanzolini, São Paulo - SP \\ Fernando José Barbin Laurindo, Prof. Dr. \\ Departamento de Engenharia de Produção \\ Escola Politécnica da USP, São Paulo - SP
}

O setor elétrico brasileiro passa por um momento de instabilidade causado pela falta de um marco regulatório apropriado. Contudo, mesmo instável, o setor ainda proporciona boas oportunidades, fazendo com que o mercado se torne extremamente competitivo. Neste contexto, o objetivo deste trabalho é analisar o papel da Tecnologia da Informação (TI) e sua influência no negócio em uma empresa do setor elétrico brasileiro, assim como a relação entre a atuação da TI dentro da organização estudada e o processo de aprendizado e da formação do conhecimento. A abordagem metodológica consistiu em uma pesquisa qualitativa composta por uma revisão da literatura e um estudo de caso. A base teórica é fundamentada em conceitos de estratégia, estratégia competitiva, aprendizado organizacional, gestão do conhecimento, competição pela TI, posicionamento da TI, alinhamento entre o negócio e a TI e sucesso e portfólio de projetos. As informações relativas ao estudo de caso foram levantadas com o uso de observações e entrevistas. O caso apresentado ilustra os conceitos apresentados na revisão, assim como a influência do aprendizado no desenvolvimento da estratégia e no papel da TI. Ao final, o trabalho abre possibilidades para a continuidade das pesquisas sobre os temas abordados.

Palavras-chave: tecnologia da informação; estratégia e gestão do conhecimento

The Brazilian electrical sector is going through a moment of instability caused by the lack of appropriated regulation. However, even though unstable, the sector still has great opportunities making the market extremely competitive. According to this scenario, this article aims to analyze Information Technology's (IT) contribution and influence on the business of a Brazilian electrical sector company, as well as the relationship between the performance of IT inside the studied organization, and learning and knowledge formation process. The methodological approach consisted in a qualitative research composed by a literature review and a case study. The theory fundamentals are supported by strategy concepts, competitive strategy, organizational learning, knowledge management, competition by IT, IT positioning, alignment between business and IT, and success and project portfolios. The presented case study illustrates the concepts described in the review and the influence of learning process in the strategy development, and the IT role. At the end, the study generates possibilities for the research community about the presented themes.

Keywords: information technology; strategy and knowledge management

\section{Introdução}

Nos últimos anos, o setor elétrico brasileiro sofreu com a instabilidade regulatória e com as indefinições de um processo de privatização não concluído. Em meados dos anos 90, com a falência das empresas estatais do setor, o governo brasileiro iniciou um processo de privatização cujo objetivo era estimular a competição e a criação de preços mais baixos aos consumidores. Parte do fracasso 
desta privatização deveu-se ao fato das empresas terem sido vendidas sem um marco regulatório. $\mathrm{O}$ resultado deste processo ficou evidente com o risco de "apagão" ocorrido em 2001, quando o país precisou adotar o racionamento e aplicar recursos em um caro programa emergencial de termoelétricas (ANUÁRIO EXAME, 2004). Mesmo com a falta de regulamentação para o setor elétrico, o processo de privatização e o risco de "apagão" trouxeram turbulência ao mercado de fornecimento de energia, fazendo com que algumas empresas buscassem oportunidades de negócios neste setor.

Este trabalho busca analisar como a Tecnologia da Informação (TI) pode auxiliar as empresas deste setor na obtenção de bons resultados, mesmo que em um cenário turbulento, assim como verificar a influência entre o processo de aprendizado e da formação do conhecimento e o posicionamento da TI.

O embasamento teórico necessário para sustentar a pesquisa inclui estratégia competitiva (PORTER, 1979 e 1996; MINTZBERG et al., 2000); aprendizado, formação e gestão de conhecimento (NONAKA e TAKEUCHI, 1997; STEWART, 1998; CAVALCANTI e GOMES, 2000), o papel da TI dentro das organizações, bem como seu alinhamento estratégico com o negócio (LAURINDO, 2002; HENDERSON e VENKATRAMAN, 1993; PORTER e MILLAR, 1985; McFARLAN, 1984, entre outros); conceitos relacionados ao sucesso de um projeto (como por exemplo Meredith e Mantel, 2002) uma vez que as aplicações de TI são normalmente implementadas por meio de projetos; e as formas apresentadas na literatura para a priorização e escolha dos projetos ou sistemas de TI, considerando, entre outros, Jiang e Klein (1999) e Moraes e Laurindo (2003).

Com o objetivo de ilustrar os conceitos apresentados na revisão da literatura, é apresentado um estudo de caso de uma empresa do setor elétrico, mais especificamente uma empresa de geração de energia elétrica, classificada pela Agência Nacional de Energia Elétrica (ANEEL), como produtor independente de energia. A empresa escolhida apresentava um rol significativo de aplicações de TI.

Tais aplicações colaboraram para a ilustração dos conceitos tanto quanto o histórico de aprendizado da empresa. Apresentar-se-á neste artigo, o seu processo produtivo, bem como seu processo de aprendizado e formação de conhecimento sobre o ambiente externo e interno o qual ela está inserida, e como a TI pode contribuir para esta empresa na obtenção de resultados, de acordo com a estratégia por ela escolhida. A análise do posicionamento estratégico adotado pela organização ao longo do tempo, do seu aprendizado e do papel da TI diante do processo produtivo da empresa estudada dará indícios de quais tipos de aplicações de TI podem contribuir para a obtenção de seus objetivos estratégicos.

Ao término da exposição do caso, o trabalho é concluído propondo estudos complementares detalhados sobre as relações entre o aprendizado e a formação de conhecimento com a formulação da estratégia, com o posicionamento da TI, com o alinhamento estratégico entre a TI e o negócio e com o portfólio de aplicações de TI.

\section{Fundamentos teóricos}

\subsection{Estratégia}

Estratégia caracteriza o esforço de uma organização para responder ao meio ambiente e atingir seus objetivos com base na análise externa e interna. O objetivo é diminuir os riscos de uma má decisão, usando como base a análise do meio ambiente e sua integração com um plano orientativo (ICHIKAWA, 1998). Para Slack et al. (2002), estratégia é um padrão global de decisões e ações que posicionam a organização em seu ambiente e têm a função de fazê-la atingir aos seus objetivos de longo prazo. O conceito de estratégia tem sido abordado de diversas formas, entre elas: plano, padrão, posição, perspectiva e truque (MINTZBERG et al., 2000); um processo de aprendizado (SENGE, 1990); desenvolvimento de competências essenciais (HAMEL e PRAHALAD, 1990); sentido de direção, foco, definição organizacional e consistência (MINTZBERG et al., 2000); competição em recursos (COLLIS e MONTGOMERY, 1995); análise, escolha e competitividade em indústrias (PORTER, 1979); e inovação (SUTTON e HARGADON, 2000). 
A estratégia competitiva consiste na ação das empresas em determinadas áreas do negócio objetivando sucesso por meio do aumento na participação no mercado, da diferenciação do mercado, ou da diferenciação dos produtos e serviços (ANSOFF, 1990). Diante disso, as organizações vêm investindo recursos em diversas áreas que sustentam sua competitividade, entre elas a TI. Dada a escassez e a disputa pelos recursos, é fundamental que estes sejam aplicados de maneira a contribuir com os objetivos da organização (McGEE e PRUSAK, 1994). A estratégia pode ser considerada como uma ferramenta que auxilie e focalize na aplicação dos recursos da organização (MINTZBERG et al., 2000).

Entretanto, para Porter (1996), não basta a racionalidade na aplicação dos recursos, pois a eficiência operacional não é suficiente para manter uma vantagem competitiva sustentável, uma vez que é facilmente replicável em diferentes empresas. Desta forma, estratégia consistiria em se posicionar de uma forma a executar atividades diferentes ou de uma forma diferente dos competidores. Porter (1996) também afirma que este posicionamento, eventualmente, deve mudar de tempos em tempos para garantir a competitividade em longo prazo. Mintzberg et al. (2000) também apresentam o conceito de estratégia flexível, mas afirmam que a tarefa, embora necessária, é difícil pela característica de direção que as estratégias de muitas organizações possuem.

As dez escolas da estratégia apresentadas por Mintzberg et al. (2000) fornecem elementos importantes para o entendimento da situação analisada neste trabalho, em particular: a escola do design, a escola do aprendizado, também discutida por Senge (1990), e a escola ambiental. A Tabela 1, apresenta, de forma resumida, as características de cada uma das dez escolas apresentadas por Mintzberg et.al. (2000). Outro conceito importante para o entendimento do estudo de caso, explorado posteriormente, foi proposto por Porter (1979), ele introduziu o conceito das três estratégias competitivas genéricas (liderança em custos, diferenciação e foco), as quais servem de base para o posicionamento estratégico das industrias.

Tabela 1 - As dez escolas da estratégia e suas características, adaptado de Mintzberg et al. (2000)

\begin{tabular}{|l|l|}
\hline Escola de Mintzberg et al. (2000) & Característica \\
\hline Escola do Design & $\begin{array}{l}\text { Formulação da estratégia como um processo de concepção } \\
\text { (informal) }\end{array}$ \\
\hline Escola do Planejamento & Formulação da estratégia como um processo formal \\
\hline Escola do Posicionamento & Formulação da estratégia como um processo analítico \\
\hline Escola Empreendedora & Formulação da estratégia como um processo visionário \\
\hline Escola Cognitiva & Formulação da estratégia como um processo mental \\
\hline Escola do Aprendizado & Formulação da estratégia como um processo emergente \\
\hline Escola do Poder & Formulação da estratégia como um processo de negociação \\
\hline Escola Cultural & Formulação da estratégia como um processo coletivo \\
\hline Escola Ambiental & $\begin{array}{l}\text { Formulação da estratégia como um processo reativo sobre o } \\
\text { contexto em que a empresa está inserida }\end{array}$ \\
\hline Escola da Configuração & Formulação da estratégia como um processo de transformação \\
\hline
\end{tabular}

A escola do aprendizado de Mintzberg et al. (2000) tem particular importância para o presente artigo, pois apresenta a relação entre o tema estratégia com, entre outros, o aprendizado e o conhecimento, e conceitos abordados ao longo da revisão da literatura e do estudo de caso. De acordo com Mintzberg et al. (2000), essa escola teve sua origem no livro A Behavioral Theory of the Firm de Cyert e March (1963) e consolidou-se com os textos de Richard Normann (1977), Chris Argyris (1976) e Donald Schon (1983). Mais recentemente, The Fifth Discipline de Peter Senge (1990) e os conceitos de gestão do conhecimento, abordagem de capacidades dinâmicas (HAMEL e PRAHALAD, 1990) e teoria do caos, foram importantes impulsos relacionados ao aprendizado que ajudaram na formação da estratégia. $\mathrm{O}$ tópico seguinte revisa conceitos relacionados ao aprendizado e à gestão do conhecimento. 


\subsection{Aprendizado, conhecimento e gestão do conhecimento}

Uma série de textos recentemente lançados na literatura tem abordado os temas aprendizado e conhecimento, entre eles destaca-se Nonaka e Takeuchi (1997) apresentando o conceito "espiral do aprendizado". Este espiral representa a criação do conhecimento dentro das organizações através da movimentação do conhecimento tácito (aquilo que sabemos implicitamente) e do explícito (aquele transmissível em linguagem formal ou sistemática). Nessa movimentação entre estes tipos de conhecimento, os autores caracterizam quatro quadrantes: socialização, exteriorização, combinação e interiorização. Outros autores como Crossan et al. (1997) apud Minstzberg et al. (2000) buscaram construir uma estrutura unificante do aprendizado organizacional explorando como o aprendizado individual promove o coletivo. Para Crossan et al. (1997) apud Mintzberg et al. (2000), o aprendizado tem lugar nos níveis individual, grupal e organizacional, sendo cada um destes níveis ligados pelos processos: intuição, interpretação, integração e institucionalização.

Os processos ilustrados acima apresentam o aprendizado e a formação do conhecimento em organizações. Entretanto, se esses processos ocorrem freqüentemente, é necessário um mecanismo que garanta o armazenamento e recuperação desse conhecimento. Stewart (1998) afirma que essa organização pode ser feita pela gestão do conhecimento. Para esse autor, gestão do conhecimento limita-se ao estoque e recuperação do aprendizado e o conhecimento das empresas. Tais informações são caracterizadas no que o autor chama de "páginas amarelas da empresa", como por exemplo, um conjunto de lições aprendidas. Posição similar também é destacada por Mintzberg et al. (2000) quando aborda os temas "empresas que aprendem" e inteligência do concorrente, que por sua vez é tratada também por Hamel e Prahalad (1990). Todavia, não se deve mapear conhecimento se não for possível ligá-lo à estratégia e ao desempenho que impulsiona a estratégia (STEWART, 1998).

Outros conceitos são apresentados na literatura para o termo gestão do conhecimento. Entre eles, o proposto por Sveiby (1998), que sugere sua classificação em áreas do conhecimento (gestão de informações e de pessoas) e níveis de percepção (individual e organizacional). Salim (2001) apud Canongia et al. (2002) conceitua gestão do conhecimento como um "processo, articulado e intencional, destinado a sustentar ou promover o desempenho global de uma organização, tendo como base a criação e a circulação do conhecimento". Para Cavalcanti e Gomes (2000), gestão do conhecimento considera quatro capitais de conhecimento, sendo três ligados a gestão interna e um a externa, formando um modelo chamado de inteligência empresarial (HAMEL e PRAHALAD, 1990; e STEWART, 1998).

É, portanto, bastante significativa a influência que o aprendizado e o conhecimento possui sobre o ambiente de uma organização. Vários artigos, como o de Nicolas (2004), abordam o impacto da gestão do conhecimento sobre o processo de tomada de decisões nas organizações. Outros autores, como Snyman e Kruger (2004), apresentam a relação entre a gestão da estratégia e a gestão do conhecimento devido à importância estratégica que a informação e o conhecimento vem desempenhando nas organizações. O caso apresentado posteriormente ilustrará como o processo de aprendizado influenciou as decisões estratégicas da organização e, conseqüentemente, o papel da TI e seu alinhamento com o negócio.

\subsection{A competição pela TI}

A TI vem mudando a forma das empresas competirem. Para Porter e Millar (1985), isso vem ocorrendo através das transformações na cadeia de valor (aumentando eficiência operacional, criando links entre as atividades internas e externas da organização e agregando valor aos clientes). As empresas que estão se sobressaindo foram desenhadas sobre uma infra-estrutura de informação. Elas possuem sistemas em suas articulações. Entretanto, o importante não é a ferramenta, mas sim o conceito por trás dela (DRUCKER, 1995). A grande maioria dos produtos possui componentes físicos e de informação e a crescente importância dada a este segundo componente mostra a importância estratégica da TI (PORTER e MILLAR, 1985). 
Embora haja a questão do "paradoxo da produtividade" (LAURINDO, 2002), i.e. questionamentos feitos por vários autores, como Willcocks e Lester (1997), acerca dos benefícios de produtividade e nos negócios por meio dos investimentos feitos em TI, há várias evidências de impactos positivos oriundos da utilização da TI. Walton (1993) afirma que em pouco tempo a TI mostrou sua importância gerando benefícios em termos de eficiência, eficácia e transformação, atingindo indivíduos, unidades funcionais e a organização como um todo. A evolução da TI foi além da automação, provocando implicações organizacionais e proporcionando às pessoas informações mais corretas, base para o aperfeiçoamento do processo decisório e desenvolvimento de produtos e serviços. A TI assume papel relevante como fonte de vantagem competitiva não só por facilitar a decisão e ação dos gestores, mas também por agregar valor aos produtos e serviços da organização (REZENDE, 2002).

Para Porter (1979), o grau de competitividade de uma indústria (e o conseqüente potencial de lucratividade), é resultante da ação de cinco forças competitivas: o poder dos compradores, o poder dos fornecedores, a ameaça de novos concorrentes, a ameaça de produtos substitutos e a rivalidade entre os competidores existentes. Porter e Millar (1985) ressaltam que esta estrutura competitiva pode ser mudada com as aplicações de TI. Além disso, a TI pode proporcionar vantagem competitiva baixando os custos das atividades de valor (são aquelas que geram o produto final) e gerando diferenciação; pode também mudar o escopo competitivo e criar novos tipos de negócios (PORTER e MILLAR, 1985). A TI pode influenciar outros fatores competitivos além dos custos e da diferenciação. O'Brien (2001) apresenta outras três estratégicas competitivas sustentadas pela TI: inovação, crescimento e aliança. A Figura 1 apresenta as cinco estratégias competitivas sustentadas pela TI na visão deste autor.

\begin{tabular}{|l|l|}
\hline Estratégia & \multicolumn{1}{c|}{ Características } \\
\hline Custo & $\begin{array}{l}\text { Produzir bens e serviços de baixo custo no setor de atuação. Pode estar relacionando também a } \\
\text { diminuição dos custos na cadeia de suprimentos a jusante e a montante. }\end{array}$ \\
\hline Diferenciação & $\begin{array}{l}\text { Envolve o desenvolvimento de formas para diferenciar produtos e serviços em relação ao dos } \\
\text { concorrentes, ou diminuir as vantagens de diferenciação dos concorrentes. Tal fator pode } \\
\text { proporcionar vantagem em determinados segmentos ou nichos de mercado. }\end{array}$ \\
\hline Inovação & $\begin{array}{l}\text { Encontrar novas maneiras de fazer negócio (PORTER e MILLAR, 1985 e HAMEL e } \\
\text { PRAHALAD, 1990). Envolve o desenvolvimento de produtos e serviços exclusivos, ou a } \\
\text { entrada em um novo ramo do mercado. Mudanças em processos empresariais para a produção } \\
\text { ou distribuição de produtos e serviços também caracterizam inovação. }\end{array}$ \\
\hline Crescimento & $\begin{array}{l}\text { É caracterizado pelo crescimento da capacidade produtiva dos bens e serviços, expansão para } \\
\text { mercados mundiais - globalização dos mercados, Slack et al. (2002) - diversificação de novos } \\
\text { produtos e serviços e integração dos produtos e serviços afins. }\end{array}$ \\
\hline Aliança & $\begin{array}{l}\text { Criação de vínculos e alianças com clientes, fornecedores, concorrentes, consultores e outras } \\
\text { empresas. Envolve, normalmente, mudanças na cadeia de suprimentos incluindo fusões, } \\
\text { aquisições, formação de empresas virtuais, acordos de marketing, manufatura ou distribuição } \\
\text { com os parceiros comerciais. }\end{array}$ \\
\hline
\end{tabular}

Figura 1 - Estratégias competitivas sustentadas pela TI adaptado de O’Brien (2001)

McFarlan (1984) indica a análise das seguintes perguntas para verificar se a TI tem impacto estratégico para uma determinada indústria e também para uma empresa:

- A TI pode criar barreiras de entrada?

- A TI pode mudar a base da competição?

- A TI pode alterar o relacionamento com fornecedores?

- A TI pode alterar o relacionamento com clientes?

- A TI pode gerar possibilidades de novos produtos?

O mesmo autor afirma que se a resposta das seguintes perguntas para uma, ou mais, for sim, então a TI representa um recurso estratégico para a organização.

Entretanto, alguns autores questionaram a importância estratégica da TI afirmando que esta vem se tornando, cada vez mais, uma commodity (CARR, 2003). Anteriormente, Lacity e Hirschheim (1993) já haviam perguntado se a TI realmente se tornara rapidamente um serviço commodity a ponto de ser 
mais bem gerenciado por grandes empresas prestadoras deste serviço. A pergunta veio pela constatação de que alguns profissionais, acadêmicos e consultores aconselharam executivos a terceirizar seus serviços de TI, mesmo sabendo que essa função pode ser chave para a competitividade da empresa. Para Di Romualdo e Gurbaxani (1998), existem três tipos de intenções relacionadas a decisão da terceirização da TI: melhoria dos sistemas de informação, impacto no negócio e exploração comercial. Cada uma destas três intenções está, de alguma forma, relacionada com mudanças na cadeia de suprimento ou a estratégia de aliança de O'Brien (2001).

Portanto, o que realmente influencia na importância estratégica da TI é seu posicionamento dentro da organização, o papel que ela representa ante suas operações e estratégia de seus negócios (LACITY et al., 1995).

\subsection{O papel da TI}

Quase todos os assuntos relacionados com a TI sofrem impacto do seu papel ou da sua percepção de importância na organização, devendo ser consideradas a importância estratégica agora e/ou no futuro destes fatores (NEUMANN et al., 1992). Existe uma série de metodologias para a determinação do posicionamento da TI na organização. Uma delas, muito disseminada e útil para atuar como meio de comunicação eficaz com a alta gerência é o grid estratégico (MCFARLAN et al.,1983; MCFARLAN, 1984). McFarlan et. al. (1983) apresentaram o conceito do grid estratégico, o qual procura descrever quais possíveis posicionamentos que a TI pode possuir em uma organização, em função das aplicações de TI existentes e das aplicações de TI planejadas para o futuro (Figura 2).

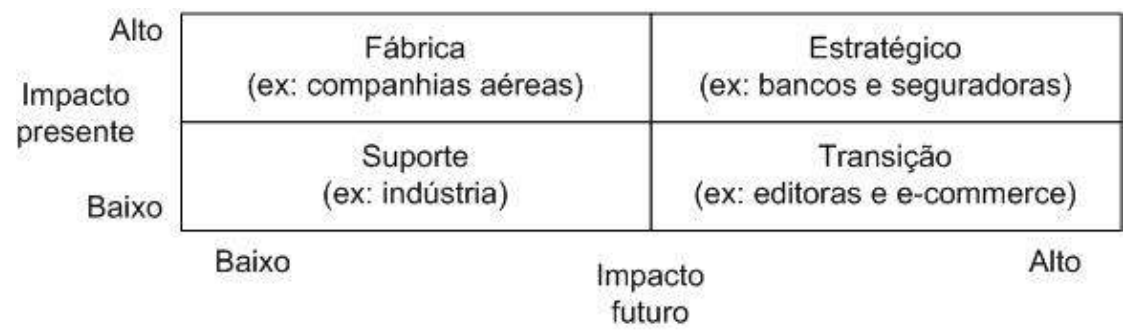

Figura 2 - Grid estratégico adaptado de McFarlan et al. (1983) e Laurindo (2002)

De acordo com McFarlan et al. (1983), o quadrante "Estratégico" caracteriza-se pelo fato de que as aplicações de TI existentes são críticas para as operações no presente e as aplicações de TI planejadas são igualmente críticas para o sucesso futuro. No quadrante "Transformação", as empresas no presente não são dependentes das aplicações de TI, mas as novas aplicações de TI são vitais para os objetivos da organização. As organizações situadas no quadrante "Fábrica" dependem das aplicações de TI para o seu funcionamento diário; entretanto, as novas aplicações não significarão vantagens futuras. Por fim, o quadrante "Suporte" abriga aquelas organizações que não são nem dependentes das aplicações de TI, nem as aplicações futuras trarão vantagens competitivas.

Em muitas organizações os executivos concluem que a TI está no quadrante "Fábrica" ou "Suporte", mas se esquecem de que as mudanças de tecnologia e as condições competitivas podem alterar este posicionamento e a forma de como a TI será gerida (McFARLAN, 1984).

Nolan (1979) apresenta seis estágios que ajudam a compreender a evolução do uso da TI em uma organização: iniciação, contágio, controle, integração, administração de dados e maturidade. A passagem de um estágio para outro implica em mudanças na forma como são escolhidas as aplicações de TI, na maneira como os recursos de TI são gerenciados, bem como na postura dos usuários.

Ao passar do estágio de administração de computadores (que inclui os três estágios iniciais) para os estágios de integração e administração de dados, muda-se o posicionamento no grid estratégico. Portanto, pode-se considerar que o posicionamento da TI está relacionado, entre outros fatores, com seu nível de maturidade. 
Além dos modelos de avaliação do papel da TI dentro das organizações apresentadas anteriormente, existem alguns outros destacados na literatura, como por exemplo a matriz de intensidade de informação de Porter e Millar (1985), que se baseia na cadeia de valor (esse conceito será apresentado posteriormente) da organização e verifica o quanto de informação está contido no produto e no processo. Outro modelo de destaque é o dos fatores críticos de sucesso (FCS) de Rockart (1979) que analisa a importância dos sistemas de informação de uma organização com base nos fatores críticos para o sucesso do negócio. Este foi concebido para dar origem a sistemas de informações gerenciais alinhados às necessidades dos gerentes, mas pode trazer impactos nos sistemas transacionais e também em outros aspectos gerenciais (como priorizar a atenção dos executivos).

A escada de avaliação de benefícios de Farbey et al. (1995) é um modelo que se propõe a sanar a limitações de outros modelos de caráter predominantemente analíticos, sendo voltado para a avaliação e para a ação. Enquanto os outros modelos viam a evolução do uso da TI seguir um curso quase que determinístico (NOLAN, 1979), ou voltados a implicações estratégicas (MCFARLAN, 1984) e se prestavam apenas a compreensão e não a ação sobre as aplicações de TI, o modelo de Farbey et al. (1995) preocupa-se em fornecer elementos para avaliação e tomada de decisão. Este modelo apresenta a escada de benefícios, sendo a importância da TI crescente à medida que se sobe na escada. O modelo apresenta oito tipos de aplicações de TI, cada um correspondente a um degrau da escada: mudanças obrigatórias ou mandatórias; automação; sistemas de valor adicionado; sistemas de informações gerenciais e sistemas de apoio à decisão; infra-estrutura; sistemas interorganizacionais; sistemas estratégicos e transformação do negócio.

O último modelo abordado neste texto foi proposto por Willcocks e Lester (1997), originado acerca da produtividade e da avaliação da TI, questionando o "paradoxo da produtividade" (LAURINDO, 2002).

Para os autores do modelo, o processo de avaliação deve conter medidas integradas que envolvam aspectos técnicos e de negócio. Deve conter informações sobre aplicações e TI a serem desenvolvidas, abandonadas e melhoradas. Deve, também, envolver todos aqueles que influenciam no processo decisório. A abordagem do ciclo de vida de Willcocks e Lester (1997) contém, entre outros pontos, o alinhamento estratégico e a priorização.

\subsection{O alinhamento estratégico da TI}

Apesar de ser estudado desde o final dos anos 80, o alinhamento estratégico da TI permanece sendo apontado como um dos principais problemas enfrentados pelos executivos de negócio e de tecnologia (PAPP e LUFTMAN, 1995; CHAN, 2002 apud BRUHN, 2004). Embora diversas pesquisas tenham comprovado o aumento de desempenho dos negócios pelo uso do alinhamento estratégico (LEDERER e MENDELOW, 1986), a falta de habilidade das empresas em realizar valor por investimentos em TI ainda ocorre (WILLCOCKS e LESTER, 1997). Para Henderson e Venkatraman (1993), tal falta de habilidade reside, em grande parte nas falhas de alinhamento entre as estratégias de negócio e de TI.

Existem diversos modelos na literatura que abordam a temática do alinhamento estratégico entre $o$ negócio e a TI. Na tentativa de entender melhor os principais modelos, Bruhn (2004) analisou cada um destes modelos, suas inter-relações e limitações. Para Bruhn (2004), estes modelos são complementares entre si, explorando e enfatizando os vários fatores de sucesso na disciplina do alinhamento estratégico: o alinhamento estratégico trata do compartilhamento de vontades e comprometimento (WALTON, 1993); é um processo iterativo (BRODBECK, 2001); envolve todos os níveis da organização (ROCKART e MORTON, 1984 e HENDERSON e VENKATRAMAN, 1993); aborda gestão de pessoas (REICH e BENBASAT, 1996); envolve esclarecimentos e uso de ferramentas compartilhadas (REZENDE e ABREU, 2001) e é sinônimo de uniformidade (PAPP e LUFTMAN, 1995). A Figura 3 apresenta, de forma resumida, a abordagem de Bruhn (2004) sobre cada um dos modelos mencionados acima. 


\begin{tabular}{|c|c|}
\hline Modelo & Características \\
\hline $\begin{array}{l}\text { Rockart e Morton } \\
\text { (1984) }\end{array}$ & $\begin{array}{l}\text { Foi o modelo precursor dos fundamentos sobre alinhamento estratégico de negócio e TI. } \\
\text { Baseia-se em elementos funcionais (estratégia e estrutura organizacional, entre outros) e suas } \\
\text { mudanças e impactos organizacionais. }\end{array}$ \\
\hline Walton (1993) & $\begin{array}{l}\text { É fundamentado na criação de uma visão estratégica. Seus objetos são o alinhamento, } \\
\text { comprometimento e as competências. Apresenta o triângulo estratégico abordando estratégia de } \\
\text { negócios, estratégia da organização e estratégia da TI. }\end{array}$ \\
\hline $\begin{array}{l}\text { Henderson e } \\
\text { Venkatraman } \\
(1993)\end{array}$ & $\begin{array}{l}\text { Modelo prático mais discutido na literatura. É baseado em fatores internos relacionados à } \\
\text { estrutura administrativa da empresa e fatores externos que compreendem o mercado e as } \\
\text { decisões envolvidas para atendê-lo. }\end{array}$ \\
\hline $\begin{array}{l}\text { Papp e Luftman } \\
\text { (1995) }\end{array}$ & $\begin{array}{l}\text { Expansão do modelo de Henderson e Venkatraman (1993) apresentando outras oito } \\
\text { perspectivas, quatro que consideram aspectos do domínio interno da organização e quatro } \\
\text { perspectivas de fusão. }\end{array}$ \\
\hline $\begin{array}{l}\text { Reich e Benbasat } \\
\text { (1996) }\end{array}$ & $\begin{array}{l}\text { Enfatiza o processo de criação e alinhamento estratégico pelo ponto de vista social, envolvendo } \\
\text { pessoas, tempo, processo de decisão e comunicação. }\end{array}$ \\
\hline $\begin{array}{l}\text { Teo e King } \\
\text { (1997) }\end{array}$ & $\begin{array}{l}\text { Apresenta uma perspectiva evolucionária entre o alinhamento e o planejamento de negócios e } \\
\text { de TI, usando de quatro estágios de evolução da integração. As contribuições para a } \\
\text { performance organizacional variam de acordo com os diferentes estágios de evolução. }\end{array}$ \\
\hline $\begin{array}{l}\text { Rezende e Abreu } \\
\text { (2001) }\end{array}$ & $\begin{array}{l}\text { Reforça o alinhamento a partir das dimensões do planejamento estratégico da TI (PETI) e de } \\
\text { seus recursos e ferramentas, planejamento estratégico empresarial (PEE) e de seus negócios e, } \\
\text { recursos sustentadores do PETI e PEE (tecnologia da informação, sistemas de informação, } \\
\text { conhecimento, pessoas e contexto organizacional). }\end{array}$ \\
\hline Brodbeck (2001) & $\begin{array}{l}\text { Expande o entendimento para além do aspecto conceitual, tratando-o como ferramenta de } \\
\text { monitoramento e gestão das estratégias e objetivos da organização ao longo do período de } \\
\text { aplicação do plano de negócios e de TI. Combina os modelos de Henderson e Venkatraman } \\
\text { (1993), Reich e Benbasat (1996) e Teo e King (1997), cruzando o alinhamento entre } \\
\text { planejamento de negócios e de TI, alinhamento entre ambientes internos e externos e } \\
\text { alinhamento temporal de forma contínua e permanente. }\end{array}$ \\
\hline
\end{tabular}

Figura 3 - Principais modelos de alinhamento estratégico, e suas características, adaptado de Bruhn (2004)

Dentre os modelos listados acima, o proposto por Henderson e Venkatraman (1993) apresenta bases importantes para o entendimento do alinhamento estratégico entre negócios e TI (LAURINDO, 2002; REZENDE, 2002). Para Henderson e Venkatraman (1993), não existe um modelo ideal para descrever e implementar o alinhamento entre a estratégia de TI e a de negócios, entretanto, existem modelos que podem auxiliar essa implementação. $\mathrm{O}$ modelo descrito por estes autores é baseado em quatro fatores (ou domínios): estratégia de negócios, estratégia de TI, infra-estrutura e processos organizacionais e infra-estrutura e processos de TI. Estes fatores são agrupados em dois blocos (ajuste estratégico e integração funcional) e procura-se identificar os dois tipos de integração dentro do domínio do negócio e da TI.

A Figura 4 ilustra o modelo de alinhamento estratégico proposto por Henderson e Venkatraman (1993), sendo que o termo integração estratégica define a ligação entre a estratégia do negócio e a estratégia de TI, refletindo os componentes externos à organização, ou seja, representa a capacidade da TI de suportar a estratégia do negócio, o que é importante devido ao papel de vantagem competitiva que a TI vem ocupando. O segundo termo, integração operacional, define a relação entre a infraestrutura e processo da organização e da TI, o qual caracteriza as vantagens operacionais trazidas pela TI como redução de custos e aumento de produtividade.

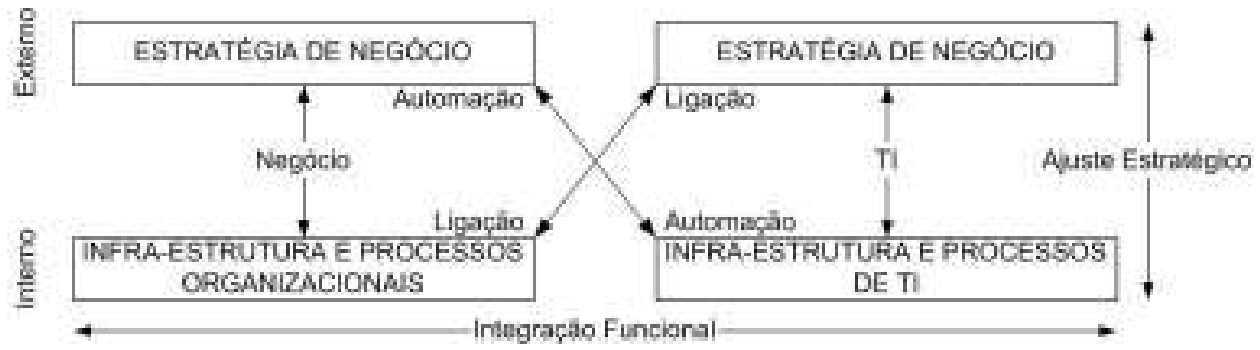

Figura 4 - Modelo do alinhamento estratégico adaptado de Henderson e Venkatraman (1993) 
Lederer e Mendelow (1986) mencionam que o planejamento da TI é reconhecidamente importante e que alguns estudos reportam que empresas que alinham a estratégia de TI à estratégia do negócio possuem desempenho melhor que as empresas que não o fazem por uma relação média de 6 para 1. Os estudos mencionados por estes autores mostram que esta melhoria é causada principalmente pela redução de custos, aumento de controle e aumento das receitas.

Drucker (1995) considera que a área na qual mais se notam benefícios proporcionados pela TI foi a de operações e que a área gerencial ainda pode ser bastante beneficiada, desde que as informações necessárias para esta área sejam buscadas no local certo. Para este autor, estas informações estão presentes em um mecanismo eficiente de controle de produção, e não somente de custo (as empresas de serviços ou que produzem itens com bastante informação agregada seriam bastante beneficiadas por novos sistemas de custeio como o activity-based conting - ABC); na forma de se visualizar os processos de toda a cadeia produtiva, ao invés de se olhar apenas para os processos internos, e na construção de riquezas pelo uso de informações de base, de produtividade, de competência e de alocação de recursos. O autor ainda coloca que essas informações tratam de questões táticas, pois as informações estratégicas vêm do ambiente externo, como o mercado ou os clientes.

\subsection{A TI e a cadeia de valor}

Um conceito importante para entender o impacto da TI é cadeia de valor da empresa, que seriam, de acordo com Porter e Millar (1985), a seqüência de operações necessárias para a empresa desempenhar seus negócios. Os autores dividiram as atividades em dois grupos: áreas de atividades-fim (diretamente relacionadas ao negócio da empresa) e áreas de atividades-meio.

- Atividades-fim (ou primárias): logística interna, operações, logística externa, marketing e vendas, prestação de serviços;

- Atividades meio (ou de suporte): infra-estrutura empresarial, gerenciamento de recursos humanos;

- Desenvolvimento de tecnologias e aquisição de insumos.

A TI permeia a cadeia de valor, influenciando não somente em como são desempenhadas as atividades, mas nas ligações entre elas, fato singular que a distingue de outras tecnologias. Para Porter e Millar (1985), a cadeia de valor de uma determinada empresa (ou indústria) pode ser representada pela Figura 5, apresentada a seguir.

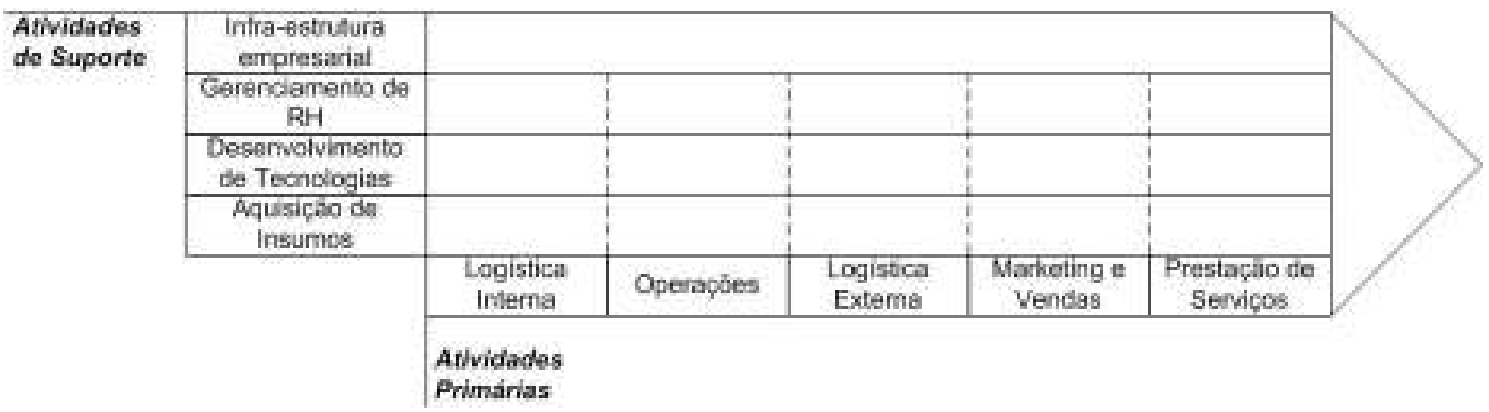

Figura 5 - Cadeia de valor da empresa estudada, adaptado de Porter e Millar (1985)

Uma outra abordagem para entender as atividades das empresas é a visão balanceada em recursos, na qual as empresas são coleções diferentes de ativos, capacidades e competências. A posse desses recursos (físicos, humanos, intangíveis ou organizacionais - processos ou cultura) permite que as organizações desempenhem atividades de uma maneira mais eficiente ou a menor custo que seus competidores (COLLIS e MONTGOMERY, 1995). Segundo alguns autores, como Duhan et al. (2001), esta abordagem é mais adequada quando se trata de empresas baseadas em conhecimento, como seria o caso, por exemplo, de empresas de educação e de consultoria. 


\subsection{Sucesso de um projeto}

O conceito e a percepção de projeto de sucesso mudam de autor para autor e principalmente de cliente para cliente e há diversos fatores que são considerados como seus condicionantes (MORAES, 2004). Verzuh (2000), define o sucesso de um projeto como sendo a entrega de um determinado produto dentro do prazo, orçamento e com alta qualidade, onde este último item é composto por dois componentes, a funcionalidade e o desempenho. $\mathrm{O}$ autor também afirma que a definição de sucesso de um projeto é muito subjetiva e que depende do alinhamento das expectativas do cliente.

Outros autores, como Meredith e Mantel (2002), definem sucesso de um projeto de forma mais abrangente e através de um conceito com quatro dimensões. A primeira se refere ao cumprimento com o orçamento definido no plano de projeto. A segunda, impacto/satisfação do cliente, está mais ligada ao atendimento das especificações técnicas e operacionais. A terceira, sucesso de negócio/direto, que está relacionado ao sucesso comercial, fatia do mercado, entre outros. A quarta e última, potencial futuro, diz respeito ao quanto o projeto é capaz de abrir novos mercados.

Embora o PMBOK (2000) afirme que os projetos são freqüentemente implementados como meios de realizar o plano estratégico das organizações, pouco este documento tem a dizer sobre o alinhamento da estratégia da organização com os projetos a serem implementados. Verzuh (2000) deixa o assunto no ar quando apresenta o conceito de que sucesso de projeto está relacionado com as expectativas do cliente. Meredith e Mantel (2002) se aproximam muito desta questão quando definem sucesso em quatro dimensões, sendo a terceira e a quarta muito próxima deste alinhamento. Kerzner (1997) afirma que a visão tradicional de sucesso, baseado nos custos, tempo e qualidade, foi consenso nos últimos 20 anos. Entretanto, a nova definição proposta pelo autor não menciona a questão do alinhamento com a estratégia da organização. Assim, é preciso distinguir o sucesso do projeto considerado como empreendimento e o sucesso do resultado final produzido pelo projeto (MORAES, 2004).

\subsection{Priorização de projetos de TI}

Existem alguns estudos e modelos que auxiliam no direcionamento da escolha e priorização dos projetos de TI dentro de uma organização. A maior parte deles baseiam-se em alguns conceitos já apresentados neste texto para a determinação do alinhamento estratégico como McFarlan et al. (1983), McFarlan (1984), Porter e Millar (1985) e Neumann et al. (1992). Estes também usam estudos que auxiliam na determinação das informações que os executivos das organizações realmente necessitam (LEDERER e MENDELOW, 1986 e 1987; DRUCKER, 1995), além de questões relacionadas aos riscos dos projetos individuais e da carteira de projetos (McFARLAN, 1981) e de questões relacionadas à natureza do comportamento humano, como resistência a mudança, perda de poder, entre outros (MARKUS, 1983).

Dos estudos e modelos desenvolvidos, pode-se destacar o proposto por Jiang e Klein (1999), que está baseado em três aspectos. Primeiramente, identificar e selecionar um critério para o que propõem o uso de modelos já desenvolvidos para determinar a necessidade de informação da organização e a relevância estratégica da TI. Em seguida, quantificar um critério para a construção de consenso sobre a importância relativa da informação. Finalmente avaliar as propostas de projeto com base nos critérios quantificados. Embora não contemplado nestes pontos, os autores destacam cuidado quanto ao comportamento das pessoas envolvidas no uso do sistema de TI, uma vez que este fator representa risco para a implementação do projeto.

O modelo proposto por Moraes e Laurindo (2003) procura determinar a escolha de projetos de TI, considerando a ligação estratégica com os objetivos da organização (avaliada através dos fatores críticos de sucesso, de acordo com o proposto por Rockart, 1979), os custos envolvidos, assim como os aspectos de riscos relacionados ao sucesso das implementações dos projetos, seguindo o conceito de portfólio de projetos. 


\section{Metodologia}

A pergunta básica que este trabalho visa responder é: como o processo de aprendizado e da formação do conhecimento influencia o posicionamento da TI em uma empresa do setor elétrico brasileiro?

Buscando responder a esta questão, este trabalho apresenta uma investigação qualitativa desenvolvida por meio de um estudo de caso. As informações foram coletadas através de entrevistas e observações (SEVERINO, 2002; MARCONI e LAKATOS, 2004). Os dados usados para o desenvolvimento da pesquisa datam dos últimos oitos anos, sendo a observação realizada durante os cinco últimos anos.

A análise dos dados levantados durante o estudo de caso foi realizada a luz dos conceitos apresentados acima, e em alguns outros mencionados durante a exposição do caso. Estes conceitos compõem o que Laurindo et al. (2001) chamam de modelos de diagnóstico. Tais modelos fornecem instrumentos e critérios para que seja diagnosticado o papel da TI nas organizações. O caso descrito a seguir procura ilustrar os conceitos apresentados acima.

A empresa estudada foi escolhida para o caso devido a pertencer ao setor de produção de energia elétrica, no qual o processo produtivo é singular, uma vez que o produto produzido (energia elétrica) não possui as mesmas características dos produtos da manufatura convencional (como por exemplo, tangibilidade, estocabilidade, entre outros), sendo mais próximo dos conceitos de serviço.

Além disso, a empresa apresentava um rol significativo de aplicações de TI. Por sua vez, a escolha deste setor deveu-se ao cenário em que ele se encontra no Brasil. Tal cenário requer uma análise competitiva criteriosa devido às incertezas causadas pela indefinição de normas.

\section{0 estudo de caso}

\subsection{Características do negócio}

A empresa estudada pertence ao setor de energia elétrica e é classificada pelo órgão regulador deste setor (ANEEL) como produtor independente de energia (de acordo com a resolução normativa $\mathrm{n}^{\mathrm{o}} 109$ de 26 de outubro de 2004 da ANEEL, um produtor independente é "pessoa jurídica ou consórcio de empresas titular de concessão, permissão ou autorização para produzir energia elétrica destinada ao comércio de toda ou parte da energia produzida, por sua conta e risco"). Seu negócio se caracteriza pela geração de energia em sistemas isolados, ou seja, onde não há a chegada de linhas de transmissão de energia.

A geração é feita por meio de usinas termoelétricas, nas quais os motores primários são movidos pela queima de óleo diesel. A entrada no mercado se inicia após a participação de um processo licitatório, ou de concorrência, realizado pelas distribuidoras de energia locais, onde a empresa ganhadora é aquela que oferece um "mix" composto por: menor tarifa pelo megawatt gerado; capacidade de potência instalada em cada localidade; planos de crescimento de potência instalada por localidade; entre outros. Terminado esse processo de concorrência, a empresa vencedora, inicia suas atividades com a instalação de novas usinas nas localidades previstas em contrato. Estas novas usinas, serão, depois de construídas, operadas por esta empresa vencedora. A empresa em questão tem, por sua vez, garantias de consumo mínimo em cada localidade, assim como um contrato por um período mínimo, além do subsídio de parte do óleo diesel utilizado.

As características necessárias para vencer as concorrências delineiam o foco principal do negócio: a operação eficiente do sistema, pois a garantia e a eficiência do fornecimento da energia está embasada no perfeito funcionamento dos equipamentos envolvidos em cada usina (motores, geradores e subestação). Desta maneira, se faz importante o conhecimento do processo produtivo da empresa e, principalmente, da cadeia de valor responsável pela produção do seu produto, a energia elétrica. 
A nomenclatura usada por Porter e Millar (1985) para a cadeia de valor pode ser adaptada de acordo com as atividades desenvolvidas pela empresa estudada, de modo a se obter um melhor entendimento sobre as atividades e o cenário analisado. Por exemplo, no que diz respeito às atividades primárias, logística interna para os autores representa, na empresa estudada, o deslocamento de peças e mão-deobra para a manutenção dos equipamentos, assim como marketing e vendas representam todo o trabalho de preparação feito para a participação nas concorrências. Nas atividades de suporte, pode-se dizer que aquisição de materiais relaciona-se, na empresa estudada, às atividades desenvolvidas pela área de suprimentos e assim por diante. A Figura 6 detalha o que representa a nomenclatura dos autores nas atividades da empresa estudada.

\begin{tabular}{|l|l|}
\hline \multicolumn{2}{|l|}{ ATIVIDADES PRIMÁRIAS } \\
\hline Porter e Millar (1985) & Empresa Estudada \\
\hline Logística Interna & $\begin{array}{l}\text { Transporte eficiente e eficaz de peças e mão-de-obra usados na } \\
\text { manutenção dos equipamentos de geração de energia elétrica }\end{array}$ \\
\hline Operações & Atividade operação do ambiente produtivo \\
\hline Logística Externa & $\begin{array}{l}\text { Transporte eficiente e eficaz das peças e serviços especializados } \\
\text { adquiridos junto a parceiros dentro e fora do Brasil }\end{array}$ \\
\hline Marketing e Vendas & $\begin{array}{l}\text { Atividades necessárias para a participação nos processos de } \\
\text { concorrência (tanto as concorrências iniciais como as de continuidade } \\
\text { de prestação dos serviços) }\end{array}$ \\
\hline Prestação de Serviços & $\begin{array}{l}\text { Incluem-se aqui as atividades de implementação das usinas, de } \\
\text { manutenção dos equipamentos e de melhoria do ambiente produtivo }\end{array}$ \\
\hline Porter e Millar (1985) & ATIVIDADES DE SUPORTE \\
\hline Infra-estrutura empresarial & Empresa Estudada \\
\hline $\begin{array}{l}\text { Gerenciamento de Recursos } \\
\text { Humanos }\end{array}$ & $\begin{array}{l}\text { Todas as atividades administrativas realizadas pela empresa, como } \\
\text { finanças (contas a pagar e contas a receber), controladoria, } \\
\text { contabilidade, entre outros }\end{array}$ \\
\hline Desenvolvimento de Tecnologias & $\begin{array}{l}\text { Relacionam-se as atividades desenvolvidas pela área de RH da } \\
\text { empresa, como contratação, aperfeiçoamento profissional, entre outros }\end{array}$ \\
\hline $\begin{array}{l}\text { Este item possui uma relação forte com as atividades de operações e } \\
\text { prestação de serviços, pois é nesta área que a análise da operação dos } \\
\text { equipamentos envolvidos no processo produtivo são transformadas em } \\
\text { melhorias tecnológicas }\end{array}$ \\
\hline Aquisição de Insumos & $\begin{array}{l}\text { Relacionam-se as atividades de desenvolvimento de novos } \\
\text { fornecedores e compras realizadas pela área de suprimentos }\end{array}$ \\
\hline
\end{tabular}

Figura 6 - Associação entre a nomenclatura usada por Porter e Millar (1985) com as atividades desempenhadas pela empresa estudada

Para Porter e Millar (1985), como visto, as atividades primárias são aquelas responsáveis pela criação física do produto. Para a empresa estudada, essas atividades representam o negócio em si. "O negócio da nossa empresa é vender energia elétrica, mas a nossa atividade principal é a manutenção...", afirmação de um dos diretores da empresa estudada. Desta forma, a aplicação de conceitos modernos de manutenção, como o conceito de manutenção preditiva (este tipo de manutenção parte do princípio de que o monitoramento regular das condições mecânicas da máquina, e do rendimento operativo dos sistemas de processo, assegurarão o intervalo máximo entre os reparos, diminuindo os custos das paradas não programadas e das manutenções corretivas, assim como aumentando a disponibilidade global das plantas), contribui para eficiência do negócio, tanto quanto as manutenções corretivas e preventivas.

A tabela 3 descreve também como a atividade de logística (interna e externa) agrega valor às atividades de operação e manutenção. A área de logística possui a função de garantir a distribuição eficiente e eficaz das peças e serviços relacionados à operação e a manutenção das usinas. Os conhecimentos e práticas de manutenção devem, então, ser apoiados por um sistema logístico que garanta a distribuição correta das peças (peça certa no momento certo) e o deslocamento das equipes técnicas envolvidas na manutenção, uma vez que o acesso às regiões do sistema é de grande dificuldade. 
As atividades relacionadas à implantação, ou atividades de projeto e instalação das usinas geradoras de energia (atividades de prestação de serviços) também merecem destaque. Segundo Slack et al. (2002), as atividades de projeto influenciam diretamente nas operações de um determinado negócio, da mesma forma que as restrições das operações influenciam nas características de projeto. A Figura 7, abaixo, representa este conceito. Visto que a operação eficiente do negócio está ligada ao sucesso da empresa, as atividades de implantação possuem um papel importante, pois suas definições podem influenciar nas operações da empresa.
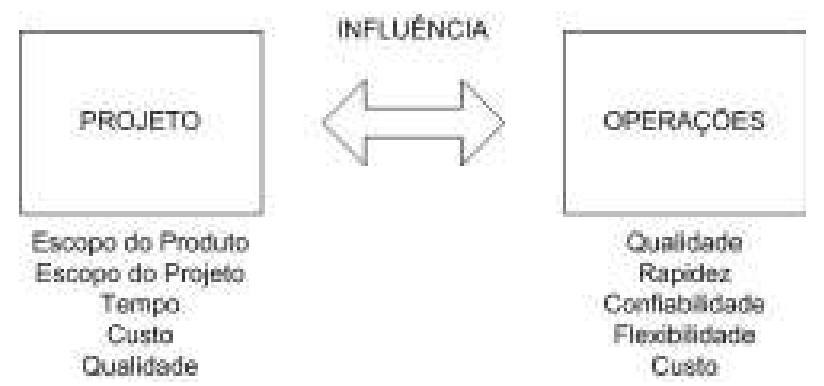

Figura 7 - Influências sobre as decisões de projeto e restrições de operações adaptado de Slack et al. (2002)

O relacionamento entre as atividades e seu respectivo impacto, conforme apresentado no parágrafo anterior, também é discutido por Porter e Millar (1985). Para os autores, esse relacionamento é direcionado a trocas orientadas por custo ou efetividade. Na empresa estudada, pode-se citar como exemplo o relacionamento entre as atividades de desenvolvimento tecnológico com as atividades de operações e prestação de serviços (melhoria). Outro exemplo de impacto está na influencia da logística em outras atividades, exemplo este que também é destacado pelos autores.

Com o conhecimento sobre o processo produtivo descrito nos parágrafos acima é possível determinar que áreas são mais importantes para a operação da empresa, assim como os relacionamentos que podem agregar mais valor ao produto com o uso da TI. Como apresentado anteriormente, há então a necessidade de se conhecer o direcionamento estratégico para a aplicação eficaz dos recursos.

\subsection{Análise estratégica da empresa estudada}

Embora a empresa estudada não possuísse um posicionamento estratégico formal, dentro do conceito das estratégias genéricas de Porter (1979), pode-se considerar que a empresa em questão utiliza a estratégia de liderança em custo no momento da entrada no mercado (ao vencer a primeira licitação), uma vez que, em sua entrada no mercado, é necessário ter custos baixos o suficiente para influenciar, positivamente, os baixos preços das tarifas apresentadas em suas propostas.

Após sua entrada em operação, a medida em que a empresa ganha experiência na condução do seu negócio, ela acumula um conhecimento que favorece a redução de custos por meio da melhoria contínua de seus processos operacionais. Esse conceito de melhoria de processos operacionais e sua influencia na redução de custos é apresentado por Slack (2002). Desta forma, pode-se considerar que a empresa estudada adquiriu uma posição diferenciada perante seus concorrentes (atuais e possíveis). Embora a empresa estudada possua uma posição diferenciada sobre seus concorrentes, isso não significa que ela passou a praticar a estratégia da diferenciação. Ao contrário disso, como o mercado é orientado a um menor preço possível para a tarifa do megawatt, seu foco na liderança em custos se mantém, pois sem isso a empresa em questão não teria condições competitivas de se manter no mercado.

O termo vantagem competitiva representa bem a situação em que a empresa estudada se encontra perante seus concorrentes. Essa vantagem competitiva é uma função direta da cadeia de valor da empresa. O posicionamento de custo desta empresa é refletido pela execução de suas atividades de valor em relação aos seus concorrentes. 
Dentro dos conceitos apresentados por Mintzberg et al. (2000), concluiu-se que a empresa estudada passou pelas escolas do design (pela aplicação da estratégia de uma maneira informal), do aprendizado (devido ao conhecimento adquirido do ambiente inserido) e da escola ambiental (visto na resposta ao ambiente imposto pelos concorrentes, clientes e pela regulação do governo sobre o setor). A figura 8, abaixo, representa a seqüência de passagem nas escolas de Mintzberg et al. (2000), na empresa estudada.

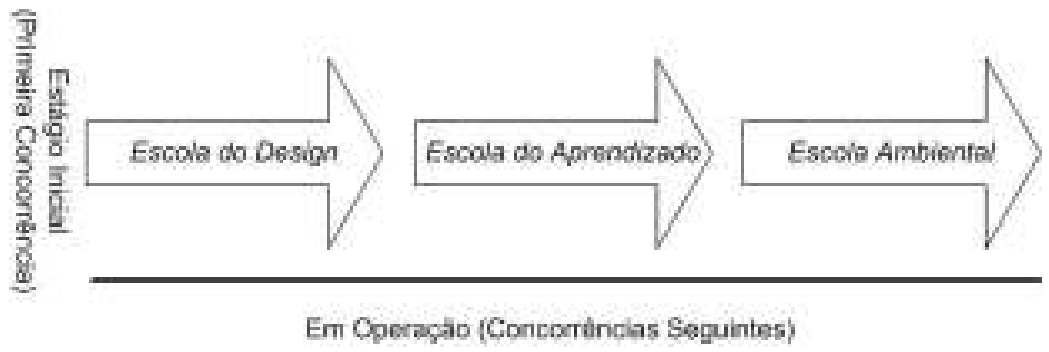

Figura 8 - Processo de aprendizado estratégico segundo as escolas de Mintzberg et al. (2000) na empresa estudada

O aprendizado sobre as operações da empresa estudada é particularmente interessante e ilustra os conceitos apresentados por Nonaka e Takeuchi (1997) e Crossan et al. (1997) apud Minstzberg et al. (2000). Muitas das pessoas que atuaram na "linha de frente" da operação da empresa estudada possuíam anos de experiência neste setor. Muitas destas pessoas vieram das antigas empresas estatais que prestavam este tipo de serviço para a comunidade. A melhoria da eficiência operacional citada nos parágrafos anteriores, e fomentada pela diretoria da empresa, adveio do conhecimento tácito de vários destes profissionais. Com o incentivo da diretoria de operações, esse conhecimento se tornou explícito, sendo transformado em manuais e procedimentos, que por sua vez, proporcionaram o ciclo de melhoria nos processos. Mesmo sem conhecer os conceitos sobre gestão do conhecimento, a empresa estudada criou um mecanismo que melhorou sua competitividade com base na circulação do conhecimento (SALIM, 2001 apud CANONGIA et al., 2002).

O caso também ilustra o aprendizado sobre os ambientes externo e interno relativos à organização (HAMEL e PRAHALAD, 1990; STEWART, 1998; CAVALCANTI e GOMES, 2000 e NICOLAS, 2004). Esse conhecimento proporcionou à empresa um direcionamento sobre suas ações, assim como investimentos em ferramentas que viabilizassem seu foco principal durante alguns anos, a redução de custos. A análise sobre o papel da TI, e seu alinhamento, ilustram algumas destas iniciativas.

\subsection{O papel da TI na organização}

Na empresa estudada, percebeu-se que o papel da TI e o seu posicionamento no grid de McFarlan et al. (1983) variou de acordo com o nível de maturidade da TI dentro da organização, com a estratégia e o posicionamento escolhido pela própria organização e com os movimentos do mercado (competidores e clientes).

Embora Drucker (1995) coloque que, em alguns casos, a TI já nasce consolidada junto com as organizações, neste caso, percebeu-se que a TI vem evoluindo de acordo com os conceitos de Nolan (1979). Como visto, este autor observou que as organizações evoluem seus conceitos em TI conforme seis estágios (Iniciação, Contágio, Controle, Integração, Administração de Dados e Maturidade). Dentro desta classificação, ao se estudar a empresa em questão, percebeu-se que sua cultura em TI evoluiu conforme apresentado na Figura 9, abaixo: 


\begin{tabular}{|l|l|}
\hline $\begin{array}{l}\text { Estágio Conforme Nolan } \\
\text { (1979) }\end{array}$ & Observações Realizadas \\
\hline Iniciação & $\begin{array}{l}\text { Uso de computadores e planilhas eletrônicas para controle de compras } \\
\text { e de processadores de texto para criação de documentos como } \\
\text { memorandos e documentos timbrados }\end{array}$ \\
\hline Contágio & $\begin{array}{l}\text { Computadores sem ligação em rede, uso de acessos individuais a } \\
\text { Internet para troca de mensagens entre as filiais recém criadas, } \\
\text { desenvolvimento de sistemas isolados para atender às demandas } \\
\text { crescentes de controle }\end{array}$ \\
\hline Controle & $\begin{array}{l}\text { Início do foco nos dados, implementação de sistemas de controle de } \\
\text { compras, financeiro e controle de manutenção e de estoque, sistemas } \\
\text { distribuídos com troca de informação em batch ao final do dia, início } \\
\text { do uso de redes de computadores locais }\end{array}$ \\
\hline Integração & $\begin{array}{l}\text { Centralização do acesso a Internet nos escritórios, instalação de redes } \\
\text { locais estruturadas, implementação de redes virtuais privadas, } \\
\text { integração do sistema de manutenção e integração dos dados do } \\
\text { sistema de compras e financeiro de hora e hora }\end{array}$ \\
\hline Administração de Dados & $\begin{array}{l}\text { Foco na administração dos dados e dos processos de negócio da } \\
\text { empresa, implementação de um sistema de gestão integrado tornando } \\
\text { o sistema com alimentação e consulta on-line }\end{array}$ \\
\hline Maturidade & $\begin{array}{l}\text { Em evolução, a empresa ainda não está totalmente madura em termos } \\
\text { de utilização e gerenciamento das aplicações de TI }\end{array}$ \\
\hline
\end{tabular}

Figura 9 - Evolução da cultura de TI na empresa estudada conforme os conceitos de Nolan (1979)

Hoje, a empresa estudada encontra-se no estágio 5, o de administração dos dados. Junto a esta evolução seu posicionamento dentro do grid estratégico de McFarlan et al. (1983) também foi alterado. Usando-se da Figura 9, percebe-se que nos dois primeiros estágios de Nolan (1979) a empresa poderia ser classificada no quadrante "Suporte", conforme os conceitos de McFarlan et al. (1983), devido a pouca importância de seus sistemas. Durante os estágios seguintes, nota-se que a empresa caminhou em direção ao quadrante "Transformação", onde a TI busca cada vez mais posicionar suas aplicações de forma a agregar um valor estratégico no futuro. $\mathrm{O}$ ato da TI em se posicionar de uma maneira a agregar mais valor ao negócio demonstra o aprendizado desta área sobre o negócio da organização (CROSSAN et al., 1997 apud MINTZBERG et al., 2000).

Outro fator que influenciou fortemente o posicionamento da TI (McFARLAN et al., 1983) dentro da organização foi a movimentação do mercado. Até o final de 2002, como o mercado estava agitado com a crise do "apagão", a empresa tinha a TI como um recurso necessário para fazer negócio e não como um recurso estratégico. A atenção voltada para a abertura de novos negócios fez com que a TI estivesse de coadjuvante nas operações da empresa. Com o desaquecimento do mercado no início de 2003, em virtude do término da crise, um grande foco na redução de custos e na otimização das operações foi dado pela diretoria da empresa. Neste momento, a TI atuou com projetos de redução de custos de deslocamento (viagens) através do uso de sistemas de videoconferência, sendo localizada dentro do quadrante "Fábrica" conforme McFarlan et al. (1983).

Outros fatores como a entrada de novas legislações, incentivos a novos planos de privatização, ou até mesmo por solicitações dos clientes, manteve o posicionamento da TI no quadrante "Fábrica" conforme McFarlan et al. (1983). Na empresa estudada, ocorreu uma situação onde um dos clientes solicitou diversas informações sobre o produto produzido, isso agregou ao produto uma grande quantidade de informação, fazendo com que a TI mais uma vez se re-posicionasse dentro da empresa (PORTER e MILLAR, 1985).

Os dois últimos parágrafos ilustram como o conhecimento sobre os ambientes internos e externos em que a organização está inserida afetam no posicionamento da TI (HAMEL e PRAHALAD, 1990; STEWART, 1998; CAVALCANTI e GOMES, 2000 e NICOLAS, 2004).

Atualmente, a empresa estudada encontra-se novamente no quadrante "Transformação" do grid estratégico de McFarlan et al. (1983) em virtude da implementação de um sistema de gestão integrado 
com foco na melhoria dos processos administrativos, atividades de suporte segundo Porter e Millar (1985) e possíveis ganhos de acordo com Drucker (1995). Este sistema também está buscando ganhos nos processos de manutenção e de logística, atividades primárias segundo Porter e Millar (1985) e de foco principal para Drucker (1995).

\subsection{O alinhamento estratégico da TI}

No que diz respeito ao alinhamento entre a estratégia de TI e a estratégia de negócio, usando como base o modelo proposto por Henderson e Venkatraman (1993), pode-se verificar que a estratégia do negócio, mesmo informalmente, direcionou, e ainda direciona as atividades de TI. Na grande maioria das vezes, a estratégia de negócio mudou a infra-estrutura do negócio que, por sua vez, buscou na TI o apoio para a execução dos seus processos. Isso pôde ser constatado nos projetos de implementação de sistemas de automação de escritório, sistemas de comunicação, sistemas de acompanhamento da produção e faturamento, sistemas de controle de manutenção corretiva e preventiva, entre outros. As figuras 10 e 11 apresentam essa perspectiva, também classificada como Execução de Estratégia por Henderson e Venkatraman (1993).

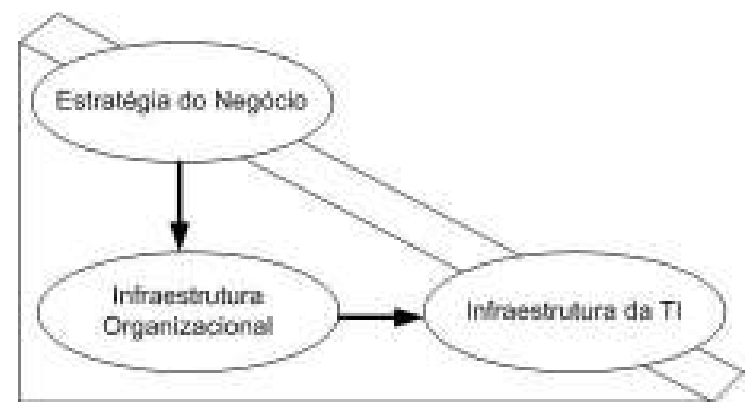

Figura 10 - Execução de Estratégia conforme Henderson e Venkatraman (1993)

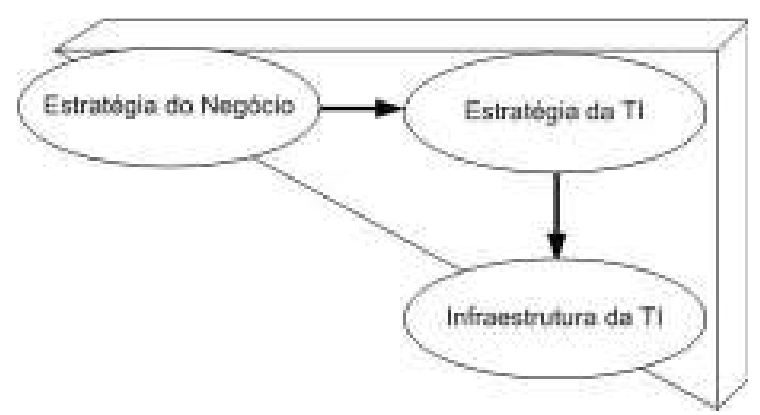

Figura 11 - Transformação Tecnológica de acordo com Henderson e Venkatraman (1993)

Por outro lado, em outras situações, a estratégia da organização influenciou a estratégia de TI a buscar um posicionamento que possibilitasse o desenvolvimento de parcerias estratégicas junto ao mercado de tecnologia. Neste caso a estratégia do negócio influencia a estratégia de TI que, por sua vez, movimenta a infra-estrutura de TI para atender as necessidades do negócio. Esta perspectiva é classificada por Henderson e Venkatraman (1993) como Transformação Tecnológica e é apresentada na figura 7. Exemplos de sistemas que possuem esta característica são: sistemas de supervisão e controle das plantas; sistemas de manutenção preditiva; sistemas de gestão da cadeia de suprimento, entre outros.

Os projetos de implementação de sistemas de gestão integrada, também podem ser classificados dentro da perspectiva de Transformação Tecnológica, pois estes projetos normalmente contam com o apoio da alta direção não possuindo restrições quanto a mudanças na infra-estrutura da organização, além disso, normalmente são projetos que atuam diretamente no redesenho dos processos. Este conceito está de acordo com Henderson e Venkatraman (1993). A Figura 12, resume o comportamento do alinhamento estratégico da TI conforme as aplicações de TI na empresa estudada. 


\begin{tabular}{|l|l|}
\hline $\begin{array}{l}\text { Perspectiva de Alinhamento } \\
\text { Estratégico }\end{array}$ & Aplicações Implementadas \\
\hline Execução de Estratégia & $\begin{array}{l}\text { Sistemas de automação de escritório, sistemas de } \\
\text { comunicação, sistemas de acompanhamento da } \\
\text { produção e faturamento, sistemas de controle de } \\
\text { manutenção corretiva e preventiva, entre outros }\end{array}$ \\
\hline Transformação Tecnológica & $\begin{array}{l}\text { Sistemas de supervisão e controle das plantas; sistemas } \\
\text { de manutenção preditiva; sistemas de gestão da cadeia } \\
\text { de suprimento, sistemas de gestão integrada, entre } \\
\text { outros }\end{array}$ \\
\hline
\end{tabular}

Figura 12 - Resumo da perspectiva de alinhamento estratégico de acordo com as aplicações de TI implementadas

\subsection{O portfólio de aplicações de TI}

A análise do ambiente da empresa com os conceitos apresentados logo acima, possibilitam a orientação de como a TI pode se posicionar junto à organização de forma a agregar mais valor ao produto e ao negócio. O aprendizado sobre os processos da empresa e o posicionamento adotado pela TI determinam, por sua vez, as aplicações que devem ser implementadas e, conseqüentemente, o portfólio de projetos de TI que fará parte do planejamento estratégico da organização.

Os modelos desenvolvidos por Jiang e Klein (1999) e Moraes e Laurindo (2003), poderiam então ser utilizados para a validação do portfólio em questão e para a determinação das prioridades de implementação dos projetos contidos dentro deste portfólio.

Embora este tipo de abordagem de portfólio não tenha sido utilizado pela empresa estudada, pôde-se constatar que o uso organizado destes conceitos faria com que os resultados fossem alcançados com mais eficiência e eficácia (resultados rápidos no momento certo). Poderia ainda facilitar no próprio alinhamento estratégico entre TI e negócio.

A aplicação destas técnicas parte do princípio de que há um conhecimento sobre os fatores externos, e da criação e execução da estratégia dentro da empresa. Embora a empresa venha adquirindo conhecimento sobre as variáveis internas e externas, ela não possui a cultura da visão e do alinhamento estratégico. Na falta dessa cultura, a aplicação destes conceitos se torna complexa, entretanto, ressalta-se que o conhecimento destes conceitos pode dar a visão de que tipo de sistema de TI pôde agregar valor em um determinado momento.

$\mathrm{Na}$ empresa estudada, como não havia essa visão de futuro, sua carteira de projetos de TI sempre foi "imediatista". Neste caso, os projetos de infra-estrutura eram sempre executados como pré-requisito para a viabilização da implementação dos sistemas. Com uma visão de futuro, a infra-estrutura, planejada e implementada, poderia ser apenas aperfeiçoada à medida que as necessidades por sistemas surgissem. A Figura 13 representa o conceito apresentado nos últimos parágrafos. 
Ambientes com Alinhamento da $\mathrm{Tl}$ ao Negócio

Projetos para Implementaçăo de Sistemas de TI

Projetos para implementaçăo de Infraestrutura de $\mathrm{TI}$

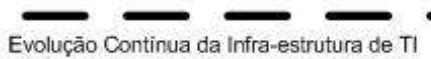

Evolução das Aplicaçöes de TI Atendendo às Necessidades do Negócio

Ambiente da Empresa Estudada

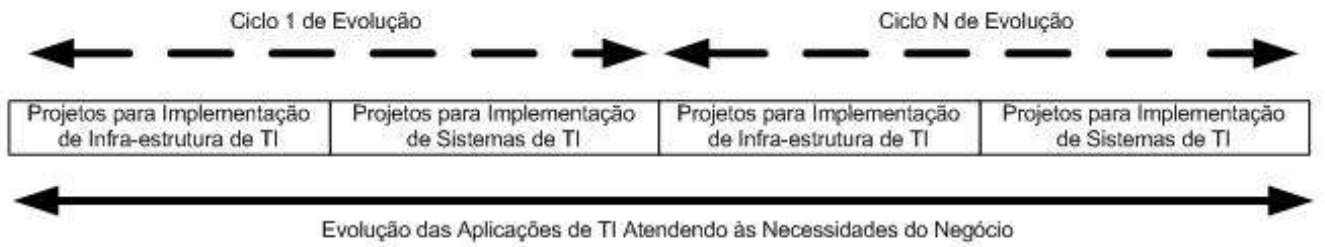

Evolução das Aplicações de TI Atendendo às Necessidades do Negócio

Figura 13 - Visão da implementação de sistemas de TI com alinhamento estratégico da TI ao negócio e na empresa estudada

\section{Considerações finais}

O mercado de energia elétrica brasileiro permanece sem definições e perspectivas concretas para os próximos meses e, talvez, anos. Além da possibilidade da criação de regulamentações que possam diminuir as margens das empresas que atuam neste setor, há a possibilidade de ocorrência de novos "apagões" e da entrada de novos concorrentes, fazendo com que o mercado se torne mais competitivo.

As empresas que atuam neste setor precisam se posicionar dentro do mercado atual e se preparar para que eventuais mudanças não diminuam as margens já utilizadas. Dentro deste cenário, a TI tem um papel fundamental dentro destas organizações, pois dependendo do posicionamento da TI dentro destas empresas, é possível fazer com que o valor agregado pelas suas aplicações traga eficiência operacional, retenção de conhecimento, reduções de custo e aumento do elo de ligação com os atuais clientes. Assim, a TI pode permitir que as empresas, atuando neste setor, sejam capazes de respostas mais ágeis e rápidas, o que é particularmente necessário em um cenário em constante mutação.

O texto apresentou o caso de uma empresa do setor de energia elétrica, seu aprendizado sobre parte das variáveis deste mercado, seu posicionamento perante o mercado, seu processo produtivo básico e a dinâmica do posicionamento da TI dentro desta organização. Esta dinâmica de posicionamento da TI mostrou como esta área agrega valor conforme a sua posição no grid estratégico de McFarlan et al. (1983) e no modelo do alinhamento estratégico de Henderson e Venkatraman (1993). Esta análise permitiu o conhecimento do alinhamento da estratégia da organização com a estratégia de TI, fazendo com que se pudesse determinar quais as aplicações de TI poderiam agregar mais valor aos negócios da empresa, formando assim um possível portfólio de projetos de TI.

Após análise e diagnóstico da situação da empresa, sugeriu-se a aplicação dos modelos propostos por Jiang e Klein (1999) e Moraes e Laurindo (2003) para a priorização dos projetos a serem implementados. Com isso, os projetos de TI desta organização poderiam ser implementados, seguindo a priorização definida e os conceitos de gestão de projetos, o que não faz parte do escopo deste artigo. $\mathrm{O}$ alinhamento entre as necessidades do negócio e a TI, abordada de diversas formas no artigo, permitem garantir que as aplicações escolhidas são realmente necessárias para o sucesso e agregam valor à organização. Além disso, pôde-se verificar como o conhecimento sobre o ambiente interno e 
externo à organização, assim como a visão e o alinhamento estratégico, podem influenciar na implementação de sistemas de TI e no ganho de eficiência do negócio.

Esse trabalho aborda uma série de conceitos e ilustra parte deles pelo uso de um caso em uma empresa do setor elétrico brasileiro. Por englobar vários conceitos, eventualmente, a análise pode ter privilegiado a abrangência em detrimento da profundidade. Por outro lado, o texto traz a tona dificuldades encontradas no setor elétrico no Brasil e apresenta a oportunidade para o desenvolvimento de estudos mais detalhados que busquem analisar o relacionamento entre a formação do conhecimento e o desenvolvimento estratégico; o relacionamento entre a formação do conhecimento e o papel da TI; o relacionamento entre a formação do conhecimento e o alinhamento estratégico entre a TI e o negócio; e o relacionamento entre a formação do conhecimento e o portfólio de aplicações de TI em empresas deste e de outros setores. Futuras pesquisas deverão contemplar estes aspectos.

\section{Referências}

ANSOFF, H. A Nova Estratégia Empresarial. 1. ed. São Paulo: Atlas, 1990. 265p.

ANUÁRIO EXAME. Corrida Contra o Apagão. v.38, n.22, p. 160-169, Nov. 2004.

ARGYRIS, C. Increasing Leadership Effectiveness. 1. ed. New York: John Wiley \& Sons, 1976. 286p.

BRODBECK, A. Alinhamento Estratégico entre Planos de Negócio e de Tecnologia de Informação: um modelo operacional para a implementação. Teste de doutorado Programa de Pós-Graduação em Administração da Universidade Federal do Rio Grande do Sul, Porto Alegre, 2001. 332p.

BRUHN, P. Alinhamento Estratégico de TI: Importância, Modelos e Relações. In: CONGRESSO ANUAL DE TECNOLOGIA DA INFORMAÇÃO - CATI. Anais. São Paulo, 2004.

CANONGIA, C.; SANTOS, D.; ZACKIEWICZ, M. Foresight, Inteligência Competitiva e Gestão do Conhecimento: Instrumentos para a Gestão da Inovação. Gestão \& Produção. v.11, n.2, p. 231-238, Mai-Ago. 2004.

CARR, N. It Doesn't Matter. Harvard Business Review. v.81, n.5, p. 41-49, may. 2003.

CAVALCANTI, M. ; GOMES, E. A Nova Riqueza das Organizações: Os capitais do Conhecimento. Revista TN Petróleo. n.16, ano 3, 2000.

CYERT, R.; MARCH, J. A Behavioral Theory of the Firm. 1. ed. Englewood Cliffs: Prentice-Hall, 1963. 332p.

COLLIS, D. ; MONTGOMERY, C. Competing on Resources: Strategy in the 1990's. Harvard Business Review. v.73, n.4, p. 118-128, Jul-Aug.1995.

DIROMUALDO, A; GURBAXANI, V. Strategic intent for IT outsourcing. Sloan Management Review. v.39, n.4, p. 67-80, summer. 1998.

DRUCKER, P. The Information Executives Truly Need. Harvard Business Review. v.73, n.1, p. 5462, Jan-Feb, 1995.

DUHAN, S.; LEVY, M.; POWELL, P. Information Systems strategies in knowledge-based SME's: the role of core competencies. European Journal of Information Systems. v.10, n.1, p.25-40, 2001. 
FARBEY, B.; LAND, F.; TARGETT, D. A taxonomy of information systems applications: The benefits evaluation ladder. European Journal of Information Systems. v.4, n.1, p. 41-50, feb. 1995.

HAMEL, G. ; PRAHALAD, C. The Core Competencies of the Corporation. Harvard Business Review. v.68, n.3, p. 79-90, May-Jun. 1990.

HENDERSON, J. ; VENKATRAMAN, N. Strategic Alignment: Levering Information Technology for Transforming Organizations. IBM Systems Journal. v.32, n.1, p. 4-16, Jan-Mar. 1993

ICHIKAWA, E. Considerações críticas sobre o planejamento estratégico. Produto \& Produção. v.2, n.2, p. 56-62, Junho. 1998.

JIANG, J.; KLEIN, G. Project Selection Criteria by Strategic Orientation. Information \& Management. v.36, n.2, p. 63-75, Aug. 1999.

KERZNER, H. Project Management: A systems approach to planning scheduling and controlling. 6. ed. New York: Van Nostrand Reinhold Company, 1997. p. 912.

LACITY, M.; HIRSCHHEIM, R. The information systems outsourcing bandwagon. Sloan Management Review. v.35, n.1, p. 73-86. fall, 1993.

LACITY, M.; WILLCOCKS, P.; FEENY, D. IT outsourcing: Maximize flexibility and control. Harvard Management Review. v.74, n.3, p. 84-93. may-june, 1995.

LAURINDO, F.J.B. Tecnologia da Informação: Eficácia nas Organizações. 1. ed. São Paulo: Futura, 2002. 248p.

LAURINDO, F.J.B.; SHIMIZU, T.; CARVALHO, M. M.; RABECHINI, R. O Papel da Tecnologia da Informação (TI) na Estratégia das Organizações. Gestão \& Produção. v. 10, n. 2, p. 160-179, ago. 2001.

LEDERER, A.; MENDELOW, A. Issues in Information Sysntems Plannig. Information \& Management. v.10, n.5, p. 245-254. May. 1986.

LEDERER, A.; MENDELOW, A. Information Resource Plannig: Overcoming Difficulties in Identifying Top Management's Objectives. MIS Quaterly. v.11, n.3, p. 389-400. Sep. 1987.

MARCONI, M.; LAKATOS, E. Metodologia cientifica. 4. ed. São Paulo: Atlas, 2004. 305p.

MARKUS, M. P. Politics, and MIS Implementation. Communications of the ACM. v.26, n.6, p. 430444. Jun. 1983.

McGEE, J.; PRUSAK, L. Gerenciamento Estratégico da Informação. 10. ed. Rio de Janeiro: Campus, 1994. 244p.

McFARLAN, F. Portfolio Approach to Information Systems. Harvard Business Review. v.59, n.5, p. 142-150, Sep-Oct. 1981.

McFARLAN, F.; McKENNEY, J.; PYBURN, P. The Information Archipelago - Plotting a Course. Harvard Business Review. v.61, n.1, p. 145-156, Jan-Feb. 1983.

McFARLAN, F. Information Technology Changes The Way You Compete. Harvard Business Review. v.62, n.3, p. 98-103, May-Jun. 1984. 
MEREDITH, J.; MANTEL, S. Project Management: A Managerial Approach. 5. ed. New York: John Wiley \& Sons, 2002. 425p.

MINTZBERG, H.; AHLSTRAND, B.; LAMPEL, J. Safari de Estratégia: Um Roteiro pela Selva do Planejamento Estratégico. 1. ed. Porto Alegre: Bookman, 2000. 299p.

MORAES, R. Condicionantes de desempenho dos projetos de software e a influência da maturidade em Gestão de Projetos Tese de doutorado. São Paulo: FEA/USP, 2004.

MORAES, R.O.; LAURINDO, F.J.B.. Um Estudo de Caso de Gestão de Portfolio de Projetos de Tecnologia da Informação. Gestão \& Produção. v.10, n.3, p. 311-328, Dez. 2003.

NEUMANN, S.; AHITUV, N.; ZVIRAN, M. A Mesure for Determinig the Strategic Relevance of IS to the Organization. Information \& Management. v.22, n.5, p. 281-299, May. 1992.

NICOLAS, R. Knowledge management impacts on decision making process. Journal of Knowledge Management. v.8, n.1, p. 20-31, 2004.

NOLAN, R. Managing the Crises in Data Processing. Harvard Business Review. v.57, n.2, p. 115-126, Mar-Apr. 1979.

NONAKA, I.; TAKEUCHI, H. Criação de Conhecimento na Empresa. 14. ed. Rio de Janeiro: Campus, 1997. 358p.

NORMANN, R. Management for Growth. 1. ed. New York: John Wiley \& Sons, 1977. 222p.

O’BRIEN, J. Sistemas de Informação e as Decisões Gerenciais na Era da Internet. 1. ed. São Paulo: Saraiva, 2001. 436p.

PAPP, R.; LUFTMAN, J. Business and I/T Strategic Alignment: New perspective and assessments. In: PROCEEDINGS OF THE ASSOCIATION FOR INFORMATION SYSTEMS, Inaugural Americas Conference on Information Systems, August, 1995.

PORTER, M. How Competitive Forces Shape Strategy. Harvard Business Review. v.57, n.6, p. 137145, Nov-Dec. 1979.

PORTER, M.; MILLAR, V. How Information Gives You Competitive Advantage. Harvard Business Review. v.63, n.4, p. 149-160, Jul-Aug. 1985.

PORTER, M. What Is Strategy? Harvard Business Review. v.74, n.6, p. 61-78, Nov-Dec. 1996.

PROJECT MANAGEMENT INSTITUTE .A Guide to the Project Management Body of Knowledge. 2. ed. Newton Square: Project Management Institute, 2000. 216p.

REICH, B.; BENBASAT, I. Measuring the linkage between business and information technology objectives. MIS Quarterly, v.20, n.1, p. 55-81, Mar. 1996.

REZENDE, D. Tecnologia da Informação Integrada à Inteligência Empresarial: Alinhamento Estratégico e Análise da Prática nas Organizações. 1. ed. São Paulo: Atlas, 2002. 155p.

REZENDE, D.; ABREU, A. Alinhamento do Planejamento Estratégico da Tecnologia da Informação ao Empresarial: Análise Preliminar de um Modelo na Prática de Grandes Empresas Brasileiras. In: ENCONTRO DA ASSOCIAÇÃO NACIONAL DE PÓS-GRADUAÇÃO E PESQUISA EM ADMINISTRAÇÃO - EnANPAD, Campinas, 2001. Anais... 
ROCKART, J. Chief Executives Define Their Own Data Needs. Harvard Business Review, v.57, n.2, p.81-92, Mar-Apr. 1979.

ROCKART, J.; MORTON, M. Implications of Changes in Information Technology for Corporate Strategy. Interfaces. v.14, n.1, p. 84-95, Jan-Feb. 1984.

SCHON, D. Organizational Learning In: MORGAN, G. (ed.) Beyond Method: Strategies for Social Research. 1. ed. Beverly Hills: Sage, 1983. 424p.

SENGE, P. The Fifth Discipline: The Art and Practice of the Learning Organization. 1. ed. New York: Doubleday, 1990. 424p.

SEVERINO, A. Metodologia do trabalho científico. 22. ed. São Paulo: Cortez, 2002. 335p.

SLACK, N. Vantagem Competitiva em Manufatura. 1. ed. São Paulo: Atlas, 2002. 218p.

SLACK, N., CHAMBERS, S.; HARRISON, A. Administração da Produção. 2. ed. São Paulo: Atlas, 2002. $747 \mathrm{p}$.

SNYMAN, R.; KRUGER, C. The interdependency between strategic management and strategic knowledge management. Journal of Knowledge Management. v.8, n.1, p. 5-19, 2004.

STEWART, T. Capital Intelectual: A Nova Vantagem Competitiva das Empresas. 11. ed. Rio de Janeiro: Campus, 1998. 237p.

SUTTON, R.; HARGADON, A. Building an Innovation Factory. Harvard Business Review. v.78, n.3, p. 157-166, May-Jun. 2000.

SVEIBY, K. A Nova Riqueza das Organizações: Patrimônio de Conhecimento. 1. ed. Rio de Janeiro: Campus, 1998. 280p.

TEO, T.; KING, W. Integration Between Business Planning and Information Systems Planning: An Evolutionary-Contingency Perspective. Journal of Management Information Systems. v.14, n.1, p. 185-214, Summer. 1997.

VERZUH, E. MBA Compacto - Gestão de Projetos. 5. ed. São Paulo: Campus, 2000. 398p.

WALTON, R. Tecnologia da Informação: O uso de TI pelas empresas que obtêm vantagem competitiva. 1. ed. São Paulo: Atlas, 1993. 215p.

WILLCOCKS, L. ; LESTER, S. In search of information technology productivity: assessment issues. Journal of the Operational Research Society. v.48, n.11, p. 1082-1094, nov. 1997. 